\title{
Immobilization of alpha lipoic acid onto polysulfone membranes to suppress hemodialysis induced oxidative stress
}

\author{
Filiz Yasar Mahlicli, Sacide Alsoy Altinkaya* \\ Department of Chemical Engineering, Izmir Institute of Technology, Gulbahce Kampusu, 35430 Urla, Izmir, Turkey
}

\section{A R T I C L E I N F O}

\section{Article history:}

Received 30 October 2012

Received in revised form

12 July 2013

Accepted 29 July 2013

Available online 16 August 2013

Keywords:

Alpha lipoic acid

Antioxidant

Hemodialysis membrane

Reactive oxygen species: self assembly of

polyelectrolyte (ionic immobilization)

\begin{abstract}
A B S T R A C T
Alpha-lipoic acid (ALA) immobilized polysulfone (PSF) hemodialysis membranes have been fabricated by the dry-wet phase inversion technique. The antioxidant properties of the membranes were evaluated in terms of inhibition of reactive oxygen species (ROS) in blood plasma, while their blood compatibilities were determined by quantitating plasma protein adsorption, platelet adhesion, activation and cytotoxicity to blood cells. The stability of ALA under typical hemodialysis conditions was improved by immobilization, and the greatest enhancement was achieved when it was sandwiched between two polyethyleneimine (PEI) layers. In vitro antioxidant activity measurements showed that ALA coated membranes are not only capable of reducing ROS levels in blood, protein adsorption and platelet activation on the membranes, but, can also prolong coagulation time. All membranes prepared were noncytotoxic to peripheral blood mononuclear cells. In addition, the high permeation rates of solutes through PSF membrane were not affected by ALA immobilization.
\end{abstract}

(c) 2013 Elsevier B.V. All rights reserved.

\section{Introduction}

During hemodialysis significant amount of reactive oxygen species is generated due to leukocyte activation [1]. These free radicals react with the proteins and lipids in blood causing oxidative stress which acts in forming three important problems - cardiovascular disease, cancer, and age-associated neurodegenerative diseases [2]. The potential cause of oxidative stress is the reduction of antioxidant defence in uremic patients. As a result, antioxidants are administrated to hemodialysis patients orally or intravenously [3-4]. Over the last 10 years, researchers focused on developing functional hemodialysis membranes to suppress hemodialysis-induced oxidative stress. The most commonly used approach is to immobilize antioxidants, vitamin E and linoleic acid, onto these membranes [5-11]. Mydlik et al. compared the effectiveness of oral vitamin $\mathrm{E}$ intake against the use of a vitamin $\mathrm{E}$ coated synthetic hemodialysis membranes on oxidative stress levels in blood [5]. They reported that vitamin E coated dialyzer provided more effective antioxidant defense than peroral administration of vitamin $\mathrm{E}$ in hemodialysis patients. Yamamoto et al. observed that vitamin $\mathrm{C}$ administration increased antioxidant activity of the vitamin-E coated membrane [7]. Kung and Yang covalently attached conjugated linoleic acid (CLA) onto industrial hemodialysis membranes manufactured from cellulose acetate, polyacrylonitrile and polysulfone. CLA immobilization not only inhibited production of ROS but also reduced platelet adhesion,

\footnotetext{
*Corresponding author. Tel.: +90 2327506658; fax: +90 2327506645 .

E-mail address: sacidealsoy@iyte.edu.tr (S.A. Altinkaya).
}

protein adsorption and prolonged blood coagulation time [8-11]. Recently, Neelakandan et al. modified poly(amide):poly(vinyl pyrrolidone) membranes with a soybean-derived phytochemical, genistein [12]. The modified membranes showed significant suppression of three clinically relevant cytokines and exhibited a dose dependent suppression of ROS levels in blood.

Unlike other antioxidants, alpha-lipoic acid (ALA) and its reduced form dihydrolipoic acid (DHLA) effectively quench a number of free radicals in both lipid and aqueous media, ALA and DHLA together have metal-chelating activity and which may have effects on regulatory proteins and on genes involved in normal growth and metabolism [13]. Therefore, ALA is widely used as a drug for prevention of various chronic diseases associated with oxidative stress, and is administered as a daily supplement for dietary purposes, antiageing, diabetes, and cardiovascular disease. In recent years, some clinical studies showed that administration of ALA therapy could decrease the biomarkers of oxidative stress in end-stage renal disease patients under hemodialysis [14] and prolong clotting time via inhibition of an intrinsic coagulation pathway [15-16]. However, instability of ALA under light or heat and its short biological half-life (30 min), may restrict its effective medical usage [17-18]. To increase its stability and provide controlled delivery, ALA was encapsulated into chitosan $[17,19]$ and chitosan-alginate complexes [18]. In addition, microcrystalline cellulose and poly(vinylidine fluoride)/cellulose ester blend membranes were functionalized with ALA and showed an excellent long-term antioxidant activity [20-21].

In this study, ALA was selected as the antioxidant to modify polysulfone (PSF) based hemodialysis membranes. The source of motivation for the present work is a need for functional hemodialysis 
membranes that are capable of suppressing oxidative stress. In addition, few have utilized the unique antioxidant properties of ALA. The PSF membranes were prepared by dry/wet phase inversion method and modified with ALA through an intermediate polyethyleneimine (PEI) layer. The antioxidant activities of free and immobilized ALA were measured using the free-radical scavenging activity of 2,2-diphenyl-1-picrylhydrazyl (DPPH) radicals. The blood compatibilities of the membranes were evaluated in terms of inhibition of reactive oxygen species in blood plasma, amount of adsorbed plasma proteins, platelet adhesion, activation and cytotoxicity on blood cells. The transport and structural properties of the membranes were also characterized. To the best of our knowledge, this is the first study that suggests immobilization of ALA onto hemodialysis membranes to prevent hemodialysis induced oxidative stress. Furthermore, the immobilization method used in this study is unique in that antioxidants are not attached on the membranes covalently through a complex chemistry. Our method is based on adsorbing positively charged, hydrophilic polyelectrolyte PEI on the negatively charged membrane surface and then site-specifically binding a carboxylic group of ALA to an ammonium group of PEI through electrostatic interactions. Thus, the cyclic disulfide bond that forms the active site of ALA becomes available on the surface of the membrane to scavenge ROS.

\section{Materials and methods}

\subsection{Materials}

PSF with a molecular weight of $26,000 \mathrm{~g} \mathrm{~mol}^{-1}, 1-2$ dichloroethane, chlorosulfonic acid, sodium dodecylsulfate (SDS) were purchased from Aldrich, 1-methyl-2-pyrrolidone (NMP) with a purity of $\gg 98 \%$ and micro BCA protein assay reagent kit were purchased from Fluka and Thermoscientific, respectively. Bovine serum albumin (MW 65,000), urea, vitamin $\mathrm{B}_{12}$, lysozyme, polyethyleneimine (pKa:8.8), 2,2-diphenyl-1-picrylhydrazyl and alphalipoic acid were all supplied by Sigma. Cell viability kits, thiazole orange (TO) and propidium iodide (PI), and the monoclonal antibodies, PAC1, FITC and CD62 PE, used for determining platelet activation were purchased from Becton Dickinson Immunocytometry Systems. $\mathrm{H}_{2} \mathrm{NaPO}_{4}$ and $\mathrm{Na}_{2} \mathrm{HPO}_{4}$ used for preparing buffer solutions were obtained from Fluka and Riedel, respectively. Water used in the experiments was distilled ion-exchanged water.

\subsection{Preparation of the membranes}

The conventional PSF was first modified by sulfonation to induce negatively charged groups $\left(\mathrm{SO}_{3}{ }^{-}\right)$before preparing the support membrane. For this purpose, PSF was dissolved in dichloroethane (DCE) to obtain a $7.5 \mathrm{wt} \%$ solution. Similarly, a solution of chlorosulfonic acid diluted in DCE (10 wt\%) was prepared and added drop-wise to the PSF solution. After mixing for $3 \mathrm{~h}$ at $24^{\circ} \mathrm{C}$, modified polymer was recovered by precipitation in $50 \mathrm{~mL}$ of methanol. Ion exchange capacity (IEC) of sulfonated PSF (SPSF) was determined as 0.9 meq. $\mathrm{g}^{-1}$.

To prepare the PSF and PSF-SPSF blend membranes, a solution of $20 \mathrm{wt} \%$ of PSF or $10 \mathrm{wt} \%$ of PSF and $10 \mathrm{wt} \%$ of SPSF in N-methyl pyrrolidone was cast onto a $10 \mathrm{~cm} \times 24 \mathrm{~cm}$ glass substrate, respectively with the aid of an automatic film applicator (Sheen Instrument Ltd., model number: $1133 \mathrm{~N}$ ) at a speed of $100 \mathrm{~mm} \mathrm{~s}^{-1}$. The initial thickness of the cast film was adjusted by a four-sided applicator with a gap size of $150 \mu \mathrm{m}$. Following casting, the support was transferred into an environmental chamber (Angelantoni Industrie, Italy, Challenge Series, model number: $\mathrm{CH} 250$ ) in which the solution was dried for $2 \mathrm{~min}$ at $25{ }^{\circ} \mathrm{C}$ and $40 \%$ relative humidity. Then, it was immediately immersed in a coagulation

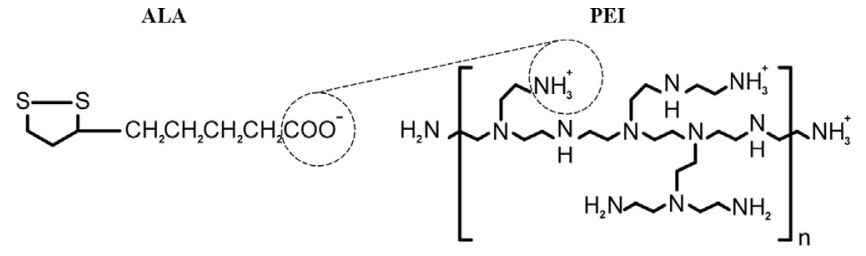

Fig. 1. Structures of PEI and ALA and their possible ionic complexation
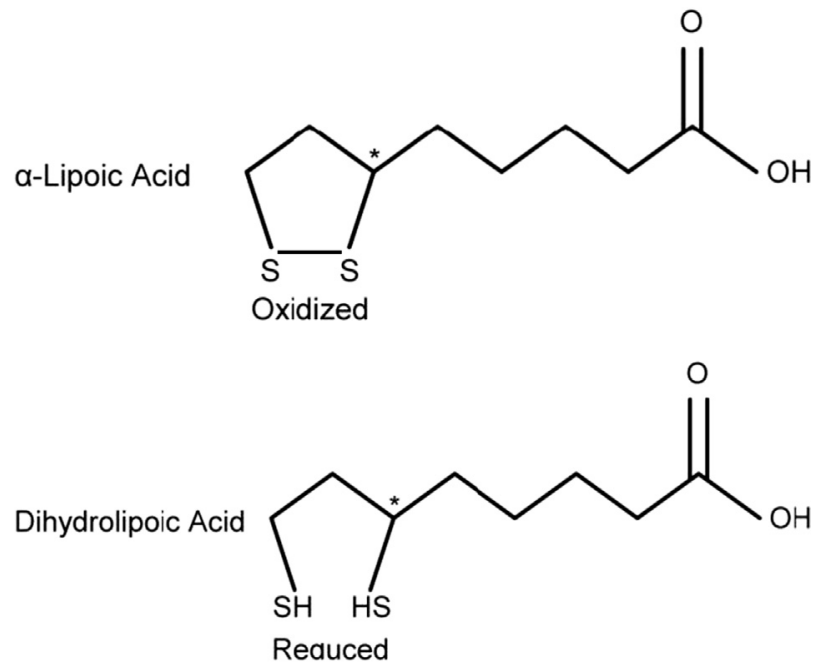

Fig. 2. Chemical structure of alpha-lipoic acid (ALA) and dihydrolipoic acid (DHLA).

bath for $18 \mathrm{~h}$, and rinsed with pure water for $1 \mathrm{~h}$. The membranes were allowed to dry further for a period of $72 \mathrm{~h}$ in a vacuum oven maintained at $100{ }^{\circ} \mathrm{C}$. They were then kept in a desiccator until their use.

The method used for immobilizing ALA is based on initially adsorbing positively charged, hydrophilic polyelectrolyte, PEI, on the negatively charged membrane surface. For this purpose, the PSF-SPSF membrane was dipped in a $1 \mathrm{mg} \mathrm{mL}^{-1}$ of PEI solution for $10 \mathrm{~min}$. The $\mathrm{pH}$ of the PEI solution was adjusted to a value of 8 by $\mathrm{HCl}$, to obtain a sufficiently protonated form, ensuring a strong bonding on the negatively charged membrane surface through electrostatic attraction. To remove excessive PEI on the surface, the membrane was rinsed with $500 \mathrm{~mL}$ water for $10 \mathrm{~min}$ and then immersed in a $1 \mathrm{mg} \mathrm{mL} \mathrm{m}^{-1}$ or $5 \mathrm{mg} \mathrm{mL}^{-1}$ of ALA solution in 5 vol\% ethanol in PBS ( $\mathrm{pH}: 7.4)$ for $30 \mathrm{~min}$ at room temperature. The amount of ALA adsorbed on the membrane ( $\mathrm{mg}$ ) was determined from the difference between the initial amount in the solution before contacting with the membrane and that after $30 \mathrm{~min}$ of contact. The adsorbed amount was divided to the surface area of the membrane to give the interfacial concentration $\left(\mathrm{mg} / \mathrm{cm}^{-2}\right)$. The concentration of ALA in the solution was measured using a UV spectrophotometer (Perkin Elmer Model No: Lambda 45) at $333 \mathrm{~nm}$. Fig. 1 shows the site-specific binding of the carboxylic group of ALA to the ammonium group of PEI through electrostatic interactions. This method allows the cyclic disulfide bond, which forms the active site of ALA, to become free on the surface of the membrane.

\subsection{Measurement of antioxidant activity}

Alpha-lipoic acid and its reduced metabolite, dihydrolipoic acid (DHLA) (Fig. 2), form a redox couple and may scavenge a wide range of reactive oxygen species such as hydroxyl radicals, nitric oxide radicals, peroxynitrite, hydrogen peroxide and hypochlorite. The antioxidant activity of ALA was measured using the freeradical scavenging activity of DPPH radicals. 
To measure free and immobilized antioxidant activities, ALA solutions freshly prepared in absolute ethanol were mixed with $0.1 \mathrm{mM}$ ethanolic DPPH in a cuvette or the membranes were immersed into $3 \mathrm{~mL}$ of $0.1 \mathrm{mM}$ ethanolic DPPH, respectively. As the odd electron of DPPH becomes paired off, the absorption vanishes and resulting decolorization is stoichiometric with respect to the number of electrons taken up. Radical scavenging activity (RSA) was then determined by measuring the decrease in the absorption of DPPH solution at $516 \mathrm{~nm}$ as follows:

$R S A \%=\left(\frac{\text { Absorbance }_{0}-\text { Absorbance }_{\text {eqb }}}{\text { Absorbance }_{0}}\right) 100$

where Absorbance $_{0}$ and Absorbance eqb $_{\text {represent }}$ absorbance measured at the beginning and at equilibrium, respectively.

To determine stability of immobilized ALA under typical hemodialysis conditions, $4 \mathrm{~cm}^{2}$ of membranes were immersed into $10 \mathrm{~mL}$ of $0.05 \mathrm{M}$ phosphate buffer solution at $\mathrm{pH} 7.4$ and $37^{\circ} \mathrm{C}$. The solution was stirred thoroughly and the membrane samples were removed from the solution after 4 and $24 \mathrm{~h}$. Then, the activity of the immobilized ALA and amount of released ALA were determined spectrophotometrically. To simulate blood flow under typical hemodialysis conditions, a dead-end ultrafiltration cell was used. $0.05 \mathrm{M}$ phosphate buffer solution at $\mathrm{pH} 7.4$ was filtered during $4 \mathrm{~h}$ at $200 \mathrm{~mL} \mathrm{~min}^{-1}$ flowrate and amount of ALA lost from the membranes was analyzed by UV-spectrophotometer. Furthermore, the membranes were treated with ethyleneoxide gas at $54{ }^{\circ} \mathrm{C}$ for $16 \mathrm{~h}$ and then incubated in laminar air flow cabinet for $24 \mathrm{~h}$ in order to remove the ethyleneoxide from the membranes. Finally, their radical scavenging activities were measured.

\subsection{Protein adsorption experiments}

Protein adsorption experiments were performed with 50\% platelet poor plasma (PPP) obtained from fresh blood (collected with citrated tubes from healthy volunteers) by centrifugation at $2800 \mathrm{rpm}$ for $15 \mathrm{~min}$ at room temperature. The membranes $(1.5 \mathrm{~cm} \times 1.5 \mathrm{~cm})$ equilibrated in $0.05 \mathrm{M}, \mathrm{pH} 7.4$ phosphate buffer at $37{ }^{\circ} \mathrm{C}$ for $15 \mathrm{~h}$, were first placed onto a 24-well plate and $1.0 \mathrm{~mL}$ of PPP was poured onto them. After incubating with PPP for $1 \mathrm{~h}$ at $37^{\circ} \mathrm{C}$, the membranes were rinsed three times with PBS, removed from the well plate, and rinsed again for $10 \mathrm{~min}$ with $50 \mathrm{~mL}$ of PBS in order to remove loosely-bond protein. Each membrane sample was placed into a glass bottle containing $1 \mathrm{wt} \%$ aqueous solution of sodium dodecylsulfate (SDS) and shaken (150 rpm) in a shaking bath for $1 \mathrm{~h}$ at room temperature to detach the adsorbed protein on the surface. In order to take into account an interference which may be caused by SDS, membrane samples not treated with protein was used as a proper control. A protein analysis kit (Micro BCA protein assay reagent kit, \#23235, Pierce, Rockford, IL, USA) based on the bicinchoninic acid (BCA) method was used to determine the protein concentration in the SDS solution. The absorbance of the solution at $562 \mathrm{~nm}$ was measured by a spectrophotometer (Perkin Elmer Model No: Lambda 45).

\subsection{Measurement of ROS levels in plasma}

Chemiluminescence (CL) method was used to measure the production of ROS in the samples using a chemiluminescence analyzer. Heparinized blood samples collected from healthy, nonsmoking donor were wrapped with aluminum foil to prevent light exposure until testing for ROS levels. $2 \mathrm{~mL}$ whole blood was incubated both with $2 \mathrm{~cm}^{2}$ modified and unmodified membranes for $4 \mathrm{~h}$ at $37^{\circ} \mathrm{C}$. Then, $50 \mu \mathrm{L}$ of blood sample was immediately placed in a 96-well plate, an aliquot of $125 \mu \mathrm{l}$ of luminol was added to the blood sample and after $5 \mathrm{~min}$ incubation, $50 \mu \mathrm{l}$ of $\mathrm{HOCl}$ was added. Luminol ( $1 \mathrm{mg} \mathrm{mL}^{-1}$ ) was used as an amplifier. The photon emission from the sample was counted at 20-s intervals at room temperature under atmospheric conditions. For each sample, the assay was performed in triplicate, and the ROS levels were expressed as CL counts.

\subsection{Platelet adhesion and activation}

In order to analyze the platelet activation, unmodified and modified PSF membranes were incubated with acid citrate dextrose (ACD)-whole blood at $37^{\circ} \mathrm{C}$ for $25 \mathrm{~min} .5 \mu \mathrm{L}$ of whole blood suspension was carefully placed into the tubes and monoclonal antibodies, PAC1, FITC and CD62 PE, were then added. Specificity of PAC1 binding is demonstrated by staining in the presence of RGDS peptide (a competitive inhibitor) as the negative control tube. Without vortex mixing, the tubes were gently mixed and incubated in the dark for $15-20 \mathrm{~min}$ at room temperature. Following the incubation period, $1 \mathrm{~mL}$ of cold $1 \mathrm{wt} \%$ paraformaldehyde was added to each tube and stored at $2-8{ }^{\circ} \mathrm{C}$ in the dark for at least $2 \mathrm{~h}$. Finally, the percentage of activated platelets was counted by Flow Cytometer (BD FacsCanto).

The morphology of adhered platelets on the modified and unmodified PSF membrane surfaces was determined by incubating the samples with platelet rich plasma (PRP) for $25 \mathrm{~min}$ at $37^{\circ} \mathrm{C}$. After incubation, the samples were gently washed to remove unbound platelets, fixed with glutaraldehyde $(2.5 \mathrm{vol} \%$ in $0.1 \mathrm{M}$ sodium cacodylate buffer, $\mathrm{pH} 7.2$ ) for $30 \mathrm{~min}$ at $4{ }^{\circ} \mathrm{C}$, and rinsed three times with PBS buffer (0.1 M, pH 7.4). The samples were then dehydrated in graded ethanol series $(30,50,70,90$, and $100 \mathrm{vol} \%$, $500 \mathrm{~mL}$ each) for $10 \mathrm{~min}$ each and air-dried. Lastly, they were sputtered with gold and analyzed with SEM (FEI-Quanta 250 FEG).

\subsection{Cell viability assay}

To determine toxic effects of the membranes, peripheral blood mononuclear cells (PBMCs) were isolated from the sample of healthy human blood by using ficol hypec gradient centrifugation. The membranes $(1.5 \mathrm{~cm} \times 1.5 \mathrm{~cm})$ were placed in 96 well plates with $200 \mu \mathrm{L}$ PBMCs sample and maintained at $37{ }^{\circ} \mathrm{C}$ for $4 \mathrm{~h}$. The number of live and dead cells labeled with Thiazole Orange (TO) and Propidium Iodide (PI), respectively, was determined with Flow cytometer (BD FacsCanto) [12].

\subsection{Blood coagulation time}

Blood coagulation time was measured by activated partial thromboplastin time (APTT). The sample membrane $\left(1 \times 1 \mathrm{~cm}^{2}\right)$ was put in a glass tube, $100 \mu \mathrm{L}$ of actin activated cephaloplastin reagent (Dade Behring Inc., USA) was added, and the tube was incubated at $37{ }^{\circ} \mathrm{C}$ for $1 \mathrm{~min}$. Then, $100 \mu \mathrm{L}$ of PPP was added to the sample solution at $37^{\circ} \mathrm{C}$, incubated for $3 \mathrm{~min}$, and finally $100 \mu \mathrm{L}$ of $0.025 \mathrm{M} \mathrm{CaCl}_{2}$ solution was added. The clotting time of the plasma solution was recorded at the first sign of fibrin formation.

\subsection{Permeation experiments}

Permeation experiments were carried out in a side-by-side diffusion cell (Permegear Membrane Transport Systems). The membrane with an area of $1.5 \mathrm{~cm}^{2}$ was placed between two chambers, each with a volume of $6 \mathrm{~mL}$. The left-side (donor) chamber was filled with phosphate buffer ( $\mathrm{pH} 7.4)$ containing desired amount of solute (urea, vitamin $\mathrm{B}_{12}$, lysozyme) while the right-side (receiver) chamber was only filled with phosphate buffer ( $\mathrm{pH}$ 7.4). The solution in each chamber was stirred sufficiently to eliminate a concentration gradient and the temperature was maintained constant at $37^{\circ} \mathrm{C}$ by circulating water through the jacket which surrounds the chambers. Samples were removed 
from each chamber at given time intervals and the concentration of lysozyme and vitamin $\mathrm{B}_{12}$ was determined by directly measuring their natural absorbance at 280 and $360 \mathrm{~nm}$, respectively. The concentration of urea was determined using commercial enzymatic kits (BT Product, Turkey). 1/100 sample/reagent ratio was used to detect the urea concentration. Samples were added to $1 \mathrm{~mL}$ of reagent, allowed to react and the concentration of urea was determined from the difference in absorbance readings at $340 \mathrm{~nm}$ taken exactly after 30 and $90 \mathrm{~s}$.

The overall mass transfer coefficient, $k_{0}$, was evaluated directly from the solute concentration data using the integrated form of the solute mass balance [22]:

$\ln \left[\frac{C_{1}\left(t_{f}\right)-C_{2}\left(t_{f}\right)}{C_{1}\left(t_{0}\right)-C_{2}\left(t_{0}\right)}\right]=k_{0} \times A\left[\frac{1}{V_{1}}-\frac{1}{V_{2}}\right]\left(t_{f}-t_{0}\right)$

where $A$ is the area of the membrane, $V_{1}$ and $V_{2}$ are the volumes of the chambers, and $C_{1}$ and $C_{2}$ are the concentrations at times $t_{0}$ and $t_{f}$, respectively. The overall mass transfer coefficient $\left(k_{0}\right)$ has contributions both from the bulk fluid and the membrane:

$\frac{1}{k_{0}}=\frac{1}{P_{m}}+\frac{2}{k_{b}}$

$P_{m}$ and $k_{b}$ in Eq. (3) correspond to the permeability and the bulk mass transfer coefficient of the solute, respectively, while the factor of two in the second term of the right-hand side of this equation reflects the presence of boundary layers in the two chambers. The bulk mass transfer coefficient was evaluated from Eq. (4) with $\alpha=0.27$ based on the specific geometry of the diffusion cell [22]:

$\frac{k_{b} r}{D_{\infty}}=\alpha \times \operatorname{Re}^{0.567} \times \mathrm{Sc}^{0.33}$

where $r$ is the radius of the cell and $D_{\infty}$ is the diffusivity of the solutes in the solution. The effective permeation coefficients of the solutes were then determined from Eq. (3).

\subsection{Surface characterization studies}

Contact angle measurements for distilled water were carried out with Attension optical tensiometer by means of a horizontal microscope, equipped with a video camera connected to a computer. The volume of liquid drop varied between 3 and $5 \mu \mathrm{L}$. The contact angle was calculated from the droplet screen image. Each reported contact angle measurement represents an average value of five separate drops on different areas of the membranes.

The XPS data were acquired with a X-ray Photoelectron Spectrometer PHI-5000 Versaprobe using an Al-monochromatic $\mathrm{X}$-ray source $(600 \mathrm{~W})$. Survey spectra $(0-1200 \mathrm{eV})$ were taken at a constant analyzer pass energy of $187.85 \mathrm{eV}$, and binding energy windows for $\mathrm{C} 1 \mathrm{~s}, \mathrm{~N} 1 \mathrm{~s}, \mathrm{O} 1 \mathrm{~s}$ and $\mathrm{S} 2 \mathrm{p}$ were obtained at a pass energy of $93.90 \mathrm{eV} .1 \mathrm{~cm} \times 1 \mathrm{~cm}$ sample was used and high-resolution spectra of $\mathrm{C} 1 \mathrm{~s}, \mathrm{~N} 1 \mathrm{~s}, \mathrm{O} 1 \mathrm{~s}$ and $\mathrm{S} 2 \mathrm{p}$ peaks were recorded at the takeoff angle of $45^{\circ}$. In order to predict which components are close to the surface, the takeoff angle between the film surface and the photoelectron energy analyzer was adjusted at $15^{\circ}$ and $75^{\circ}$. Each peak was deconvoluted by assuming a Gaussian distribution and the area under the curve was calculated by using Microcal Origin software.

To determine the surface roughness of the membranes, a topographical map of the membrane surfaces was obtained with Atomic Force Microscopy (AFM) on a Nanomagnetics Instrument model. $3 \mu \mathrm{m} \times 3 \mu \mathrm{m}$ surface was scanned with $512 \times 512$ pixel resolution using a silicon tip attached to a cantilever, while maintaining a constant force between the tip and the sample.

\subsection{Data analysis}

All the measurements were carried out with at least 3 membranes produced from three different batches. For each batch, three experiments were run in parallel, thus, total of 9 measurements were taken and the results were expressed as an average of these 9 measurements \pm standart error. The data were analyzed with the statistical software Minitab 15 using Student's paired $t$ test. The probability $(p)$ values less than $0.05(p<0.05)$ were considered to be statistically significant differences.

\section{Result and discussion}

This study aims to develop functional PSF membranes through $\alpha-$ lipoic acid immobilization and investigate the in vitro effects of this modification on blood compatibility of the membranes, especially on the inhibition of reactive oxygen species in blood plasma. To achieve this task, 2 uncoated (PSF and PSF-SPSF) and 3 coated membranes (PEI-ALA-I, PEI-ALA-II, PEI-ALA-III) were prepared as listed in Table 1 . The coated membranes were manufactured by first adsorbing a positively charged, hydrophilic polyelectrolyte PEI on the negatively charged PSF-SPSF membrane surface and then binding ALA to PEI through electrostatic interactions. In the case of PEI-ALA-II membrane, ALA was sandwiched between two PEI layers, forming the outermost layer of the PEI-ALA-I and PEI-ALA-III membranes.

\subsection{Quantification of amount of ALA in membrane and release of ALA from the membranes}

It is crucial to determine the amount of ALA immobilized in the membrane and the potential loss of ALA during typical hemodialysis period. Fig. 3 shows that at low ALA concentration $\left(1 \mathrm{mg} \mathrm{mL}^{-1}\right)$,

Table 1

Codes of the unmodified and modified PSF membranes.

\begin{tabular}{llllll}
\hline $\begin{array}{l}\text { Code of } \\
\text { membrane }\end{array}$ & $\begin{array}{l}\text { Weight } \\
\text { percentages } \\
\text { (wt\%) }\end{array}$ & $\begin{array}{l}\text { Molecule type } \\
\text { on the last layer }\end{array}$ & $\begin{array}{l}\text { ALA concentration } \\
\left(\mathbf{m g ~ m L}^{-\mathbf{1}}\right)\end{array}$ \\
\cline { 2 - 4 } & PSF & SPSF & NMP & & \\
\hline PSF & 20 & 0 & 80 & - & - \\
PSF-SPSF & 10 & 10 & 80 & - & - \\
PEI-ALA-I & 10 & 10 & 80 & ALA & 1 \\
PEI-ALA-II & 10 & 10 & 80 & PEI & 1 \\
PEI-ALA-III & 10 & 10 & 80 & ALA & 5 \\
\hline
\end{tabular}

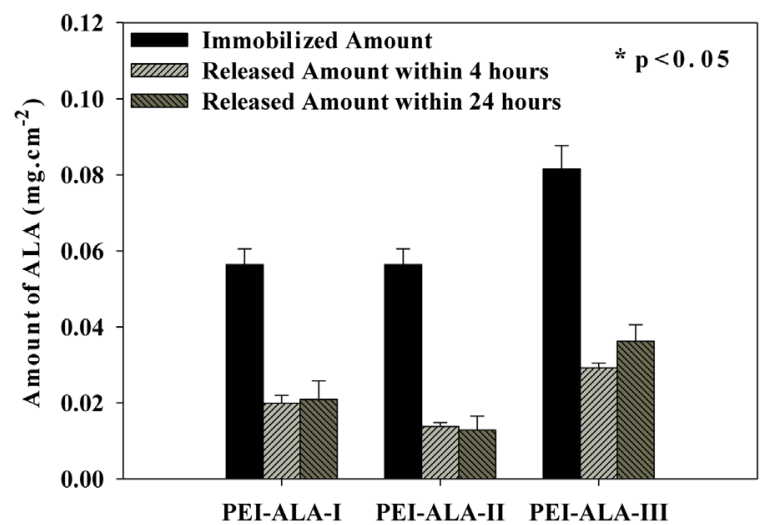

Fig. 3. Amount of immobilized and released ALA. Immobilized amount of ALA for PEI-ALA-III membrane is statistically different than that of PEI-ALA-I and PEI-ALAII membranes $(p<0.05)$. Released amounts of ALA for each membrane are statistically different from each other $(p<0.05)$. 
more than $50 \%$ of ALA added to the coating solution was retained in the final membrane. Upon increase in ALA concentration in the solution to $5 \mathrm{mg} \mathrm{mL}^{-1}$, the ALA loading of the final membrane, PEIALA-III, slightly increased compared with the amount immobilized in PEI-ALA-I membrane.

The stabilities of membranes within 4 (typical hemodialysis time) and $24 \mathrm{~h}$ were also demonstrated in Fig. 3. The statistical analysis has shown that the amounts of ALA released from the membranes at the end of 4 and $24 \mathrm{~h}$ are not significantly different from each other $(p<0.05)$. As expected, the lowest amount of ALA release occurred from the PEI-ALA-II membrane since ALA was sandwiched between two PEI layers. Compared with this membrane, the fraction of ALA leached out from the PEI-ALA-I and PEIALA-III membranes relative to the amount immobilized into these membranes initially is higher due to direct contact of ALA with the solution. For all cases most of the loaded ALA retained within the membranes after incubating with PBS for 4 and $24 \mathrm{~h}$, implying a sufficiently strong PEI-ALA complex formation. This results because at $\mathrm{pH}$ 7.4 PEI is highly positively charged ( $\mathrm{pKa}=8.8$ ) while ALA is highly negatively charged $(\mathrm{pKa}=5.2)$ [23] with degree of ionization of $96 \%$ and $99 \%$, respectively. The loss of ALA from the membranes was determined not only at the static condition but also under a $200 \mathrm{~mL} / \mathrm{min}$ flowrate which is a typical value for blood flow during hemodialysis. The loss from a $2 \mathrm{~m}^{2}$ area is $0.097 \mathrm{mg} \mathrm{mL}^{-1}$ and $0.104 \mathrm{mg} \mathrm{mL}^{-1}$ for no flow and flow conditions, respectively. Both values are comparable to the amount orally administered $\left(0.100 \mathrm{mg} \mathrm{mL}^{-1}\right)$ to the patients in clinical studies [14,24], thus, ALA released from the membranes does not hinder their use in hemodialysis.

\subsection{Surface characterization of PSF membranes}

Fig. 4 shows that blending PSF with SPSF improved its hydrophilic character as confirmed by the drop in the water contact angle values. No significant decrease in the contact angle values was observed through ALA immobilization on the surface of the blend membrane due to presence of hydrophobic groups in addition to hydrophilic groups in the structure of ALA. On the other hand, the contact angle of the PEI-ALA-II membrane was found significantly lower $(p<0.05)$ than that of the PSF-SPSF blend membrane since hydrophilic polyelectrolyte PEI, forms the last layer of this membrane.

XPS evaluation spectra of two different ALA coated PSF membranes are shown in Fig. 5. In order to determine which component is located close to the surface, the low angle $\left(15^{\circ}\right)$ measurements

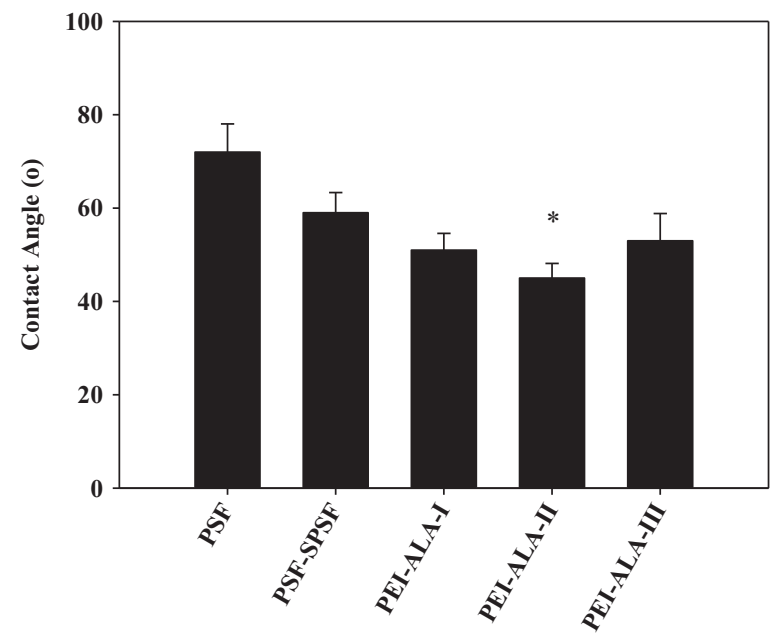

Fig. 4. Water contact angle of PSF membranes. ${ }^{*}$ Contact angle of PEI-ALA-II membrane is statistically different from that of PSF-SPSF membrane $(p<0.05)$. were performed and the ratio of the areas under the deconvoluted peaks obtained with the PEI-ALA-I and PEI-ALA-II membranes were calculated.

N1s high-resolution spectra, gives mainly charged amine group nitrogen $\left(-\mathrm{NH}_{3}{ }^{+}\right)$peak at $400.7 \mathrm{eV}$ as shown in Fig. 5b. The peak for uncharged amine group $\left(-\mathrm{NH}_{2}\right)$ was not observed since $96 \%$ of the amine groups of PEI are protonated. It is seen from Table 2 that the area for N1s peak obtained at both $15^{\circ}$ and $75^{\circ}$ with PEI-ALA-II membrane is higher than that for the PEI-ALA-I membrane. The result at $15^{\circ}$ simply indicates the presence of more $-\mathrm{NH}_{3}{ }^{+}$groups near the surface of the PEI-ALA-II membrane, hence, proving that PEI forms the last layer of this membrane. The higher value of the area at $75^{\circ}$ for the PEI-ALA-II membrane results from the presence of two PEI layers where ALA is sandwiched between these layers.

The S2p signal consists of three deconvoluted peaks (Fig. 5c). The first peak situated at $162.7 \mathrm{eV}$, is the signal of the sulfur bonded to carbon or hydrogen $(-\mathrm{S}-\mathrm{C}$ or $-\mathrm{S}-\mathrm{H})$, the second peak situated at $164.1 \mathrm{eV}$, is the signal of the elemental S $(-\mathrm{S}-\mathrm{S})$, and the signal at higher binding energy $(167.1 \mathrm{eV})$ represents the oxidized sulfur species $\left(-\mathrm{SO}_{3}{ }^{-2}\right.$ or $\left.-\mathrm{SO}_{2}\right)$. Larger area of the peak at $162.7 \mathrm{eV}$ and $164.1 \mathrm{eV}$, recorded at $15^{\circ}$ for the PEI-ALA-I membrane compared with the PEI-ALA-II (Table 2) confirms the presence of ALA as the last layer of this membrane since nonoxidized $S(-S-S$, $-\mathrm{S}-\mathrm{H}$ or $-\mathrm{S}-\mathrm{C}$ ) exists only in the structure of ALA. This result also confirms that the cyclic disulfide bond, the active site of ALA, is available on the surface as proposed at the beginning of this study. The ratio of the peak areas at $167.1 \mathrm{eV}$ is close to 1 since these peaks result from $\mathrm{SO}_{3}{ }^{-2}$ groups in the support membrane common to both PEI-ALA-I and PEI-ALA-II membranes.

The high-resolution C1s spectrum (Fig. 5d) shows four deconvoluted peaks as follows: the aliphatic carbon $(-\mathrm{C}-\mathrm{C}-$ or $-\mathrm{C}-\mathrm{H}$ at $285.1 \mathrm{eV})$, carbon bonded to the amine groups $\left(-\mathrm{HC}-\mathrm{NR}_{2}\right.$, where $\mathrm{R}$ is $\mathrm{C}$ or $\mathrm{H}$, at $286.5 \mathrm{eV}$ ), the carboxyl carbon $(-\mathrm{COO}-$ at $288.1 \mathrm{eV}$ ) and carbon bonded to sulfur (-C-S- at $284.1 \mathrm{eV})$.

The 01s signal consists of two deconvoluted peaks (Fig. 5e). The first peak situated at $532.4 \mathrm{eV}$ represents the $\left(\mathrm{SO}_{3}{ }^{-2}\right)$, and the second peak situated at $530.4 \mathrm{eV}$ represents the carboxylic oxygen atom $\left(\mathrm{COO}^{-}\right)$.

The surface roughness of the membranes was obtained from the analysis of AFM images shown in Fig. 6. The unmodified PSF membrane had the smoothest surface with an average value of $74 \mathrm{~nm}$ while sulfonation significantly increased the surface roughness to $242 \mathrm{~nm}$. On the other hand, the layer by layer deposition of PEI/ALA $(103 \mathrm{~nm})$ or PEI/ALA/PEI $(98 \mathrm{~nm})$ on the PSF-SPSF membrane improved the smoothness of the surface. This can be explained by the energy-minimization process taken place on the surface of the support membrane where PEI undergoes deformation to minimize the surface area as a result of enhanced diffusional mobility of linear PEI chains.

\subsection{The antioxidant activity of free $\alpha$-lipoic acid and $\alpha$-lipoic acid immobilized membranes}

The radical scavenging activities (RSA) of free and immobilized ALA were calculated with Eq. (1) and the results are plotted in Fig. 7. The initial antioxidant activities (10th minute) of free ALA are higher than those of the immobilized ones due to increased mass transfer resistance for the DPPH radical to reach active sites of the ALA and limited accessibility to these sites. On the other hand, at the end of $4 \mathrm{~h}$, immobilized ALA has higher activities since the antioxidant activity of free ALA is stable for only 10 min (data not shown). Instability of ALA under light and heat and its short biological half-life has also been reported by other studies [17-18]. The highest antioxidant activity was obtained with the PEI-ALA-I membrane. This is not only due to the conserving activity of ALA between two PEI layers, but also due to fewer ALA leached out 

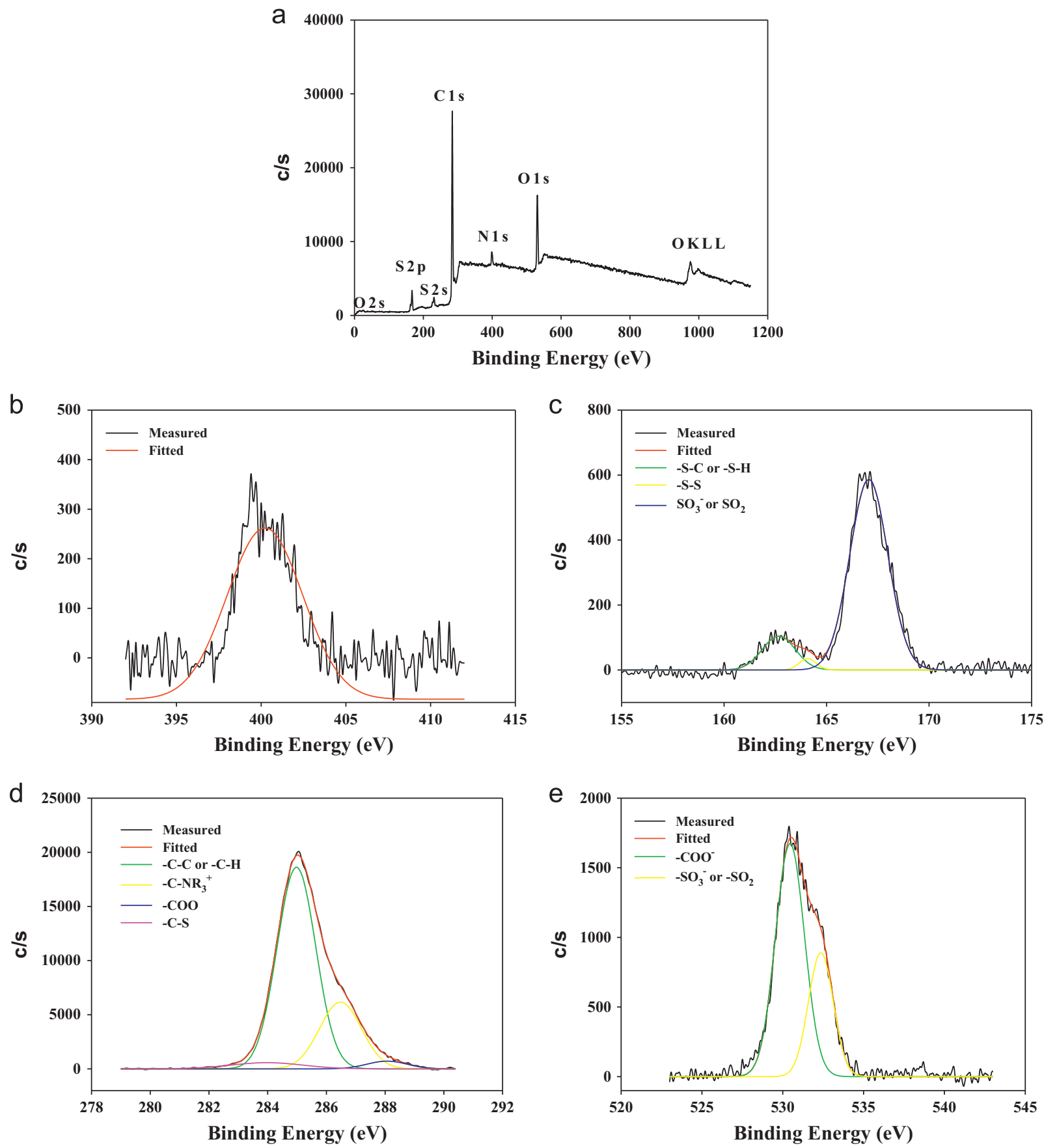

Fig. 5. XPS spectra of PEI-ALA-I membrane for (a) survey at $45^{\circ}$, (b) N 1s, (c) S 2 p, (d) C 1 s and (e) 01 s peaks at $15^{\circ}$.

Table 2

The ratio of calculated peak areas of the PEI-ALA-I membrane to those of PEI-ALAII membrane.

\begin{tabular}{|c|c|c|c|c|}
\hline Main peaks & N1s & & S2p & \\
\hline Deconvoluted peaks & $-\mathrm{NH}_{\mathbf{3}}{ }^{+}$ & $-\mathbf{S}-\mathrm{C}$ or $-\mathrm{S}-\mathrm{H}$ & $-\mathbf{S}-\mathbf{S}$ & $-\mathbf{S}-\mathbf{0}$ \\
\hline Core level $(\mathrm{eV})$ & 400.7 & 162.7 & 164.1 & 167.1 \\
\hline \multicolumn{5}{|l|}{ Takeoff angle (deg) } \\
\hline 15 & 0.93 & 1.88 & 2.84 & 0.97 \\
\hline 75 & 0.85 & 1.34 & 1.51 & 1.04 \\
\hline
\end{tabular}

from this membrane during $4 \mathrm{~h}$. Although the initial antioxidant activity of the PEI-ALA-III membrane is higher than that of the PEI-ALA-I membrane due to higher ALA loading in this membrane, their activities are almost the same at the end of $4 \mathrm{~h}$. The results in Fig. 7 indicate that ALA can maintain its antioxidant activity during typical hemodialysis time by immobilizing onto the membrane, especially between two hydrophilic polyelectrolyte layers.

\subsection{Determination of immobilized $\alpha$-lipoic acid stability}

The stability of immobilized ALA was determined by storing the membranes in $\mathrm{pH} 7.4 \mathrm{PBS}$ at $37^{\circ} \mathrm{C}$ for a period of $4 \mathrm{~h}$. The retained antioxidant activities of the two membranes, PEI-ALA-I and PEIALA-III, are similar (Fig. 8) since they include almost the same amount of ALA at the end of storage period in PBS. The resistances of the membranes to sterilization conditions were also evaluated by measuring their radical scavenging activities after treatment with ethyleneoxide. The results demonstrated that the activity of ALA immobilized on PEI-ALA-I and PEI-ALA-II membranes decreased by $27 \%$ and $19 \%$, respectively. Immobilization of ALA between two PEI 
a

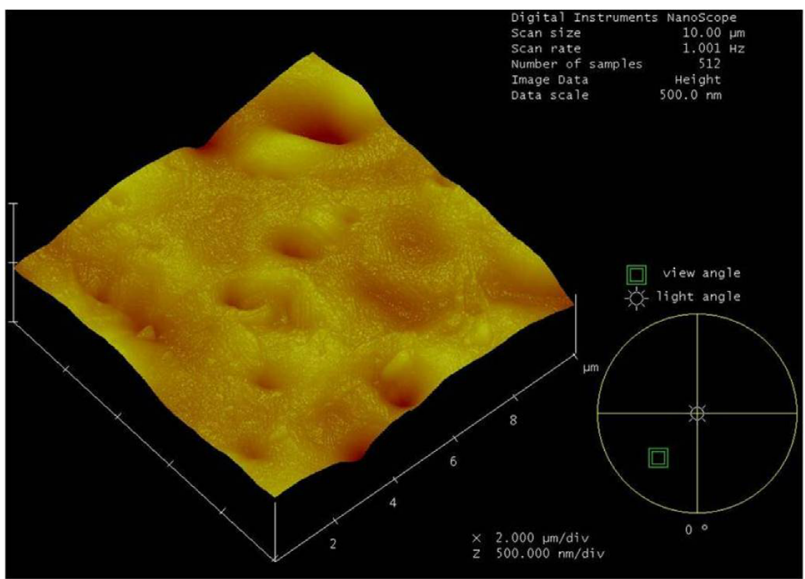

C

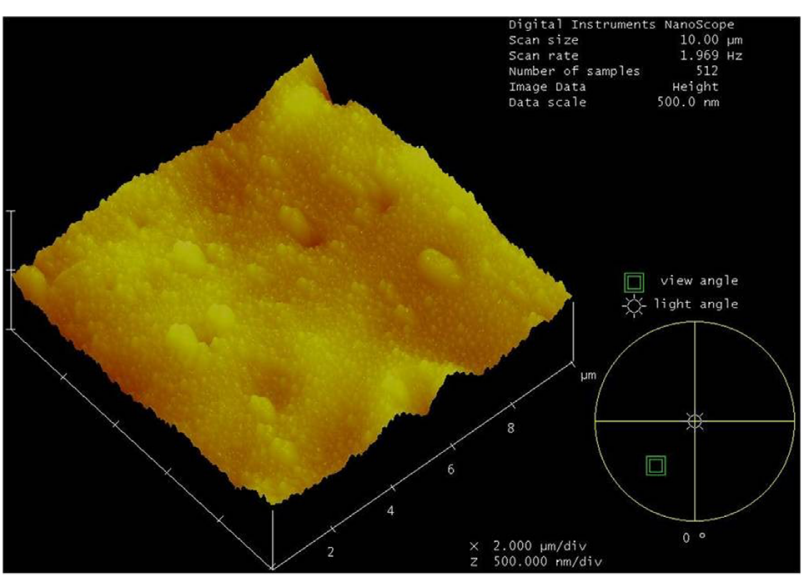

b

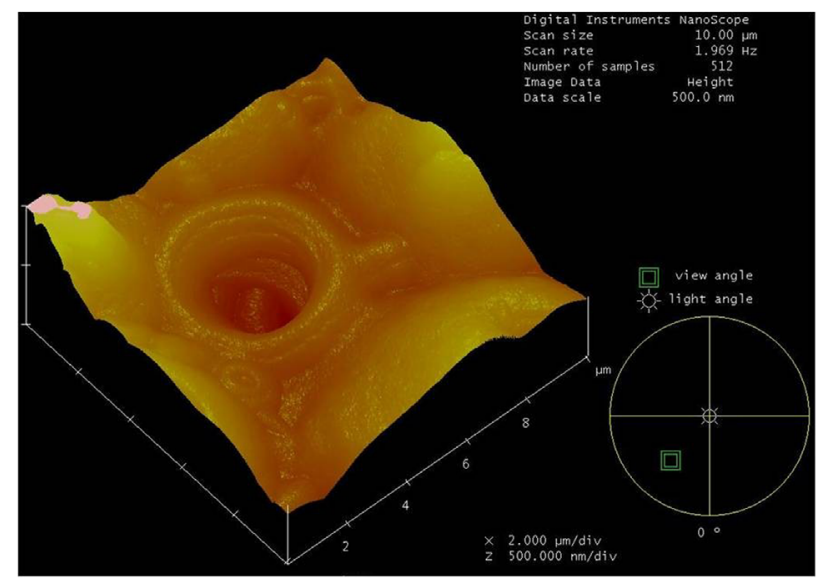

d

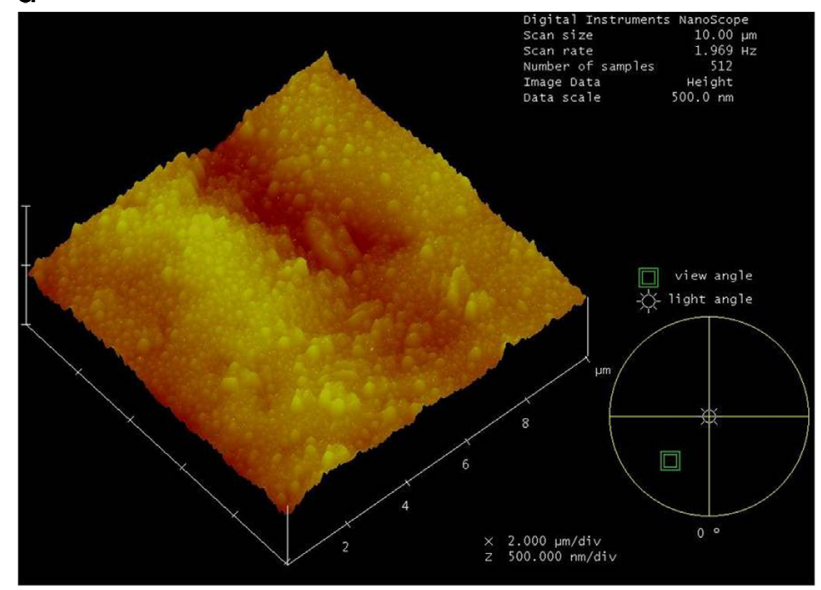

Fig. 6. AFM images of (a) PSF, (b) PSF-SPSF and (c) PEI-ALA-I, (d) PEI-ALA-II membranes.

layers caused less activity loss during sterilization and storage in PBS compared to the case that ALA was on the outermost layer of the assembly.

\subsection{Protein adsorption capacity of PSF membranes}

The amount of plasma protein adsorbed on the membranes was determined since this is the key phenomenon of hemocompatibility. The highest plasma protein adsorption occured on most hydrophobic PSF membranes, whereas blending PSF with SPSF and coating this blend membrane with PEI-ALA layer reduced protein adsorption by $24 \%$ and approximately $40 \%$, respectively, as seen in Fig. 9. Although the PSF membrane has the smoothest surface, less protein binding to the PSF-SPSF and PEI-ALA deposited membranes is related to their more hydrophilic character. In addition, the blend membrane, PSF-SPSF, and the ALA immobilized membranes, PEI-ALA-I and PEI-ALA-III, carry negatively charged groups on their surfaces that can repel similarly charged blood proteins. The PEI/ALA or PEI/ALA/PEI coated membranes adsorb less protein than the PSF-SPSF membrane since their surfaces are much more smooth.

\subsection{Platelet adhesion and activation}

Platelet activation on different membranes was determined because they play a crucial role in coagulation by secreting or releasing prothrombotic factors. Fig. 10 shows that the highest platelet activation occurred on the PSF and PSF-SPSF membranes, on the other hand, ALA immobilization remarkably decreased the activation $(p<0.05)$. The suppression of platelet activation on the modified membranes can be attributed to their lower protein adsorption capacities since the activation of intrinsic coagulation, platelet adhesion and aggregation may depend on the composition and conformation of the protein layer adsorbed onto the surface. The differences in the platelet activation on the PEI-ALA deposited membranes were found insignificant $(p>0.05)$

The morphology and activation of adhered platelet on the uncoated and coated surfaces after incubation with PRP were also examined by SEM analysis. Fig. 11 shows that numerous adhered platelets were observed on the SPSF-PSF blend membrane compared with those on the PEI-ALA coated membranes. The morphology of adhered platelets can be used as an indication of the platelet activation. As can be seen from Fig. 11, platelets on the surface of the SPSF-PSF membrane lost the discoid shape indicating the beginning of the activation. ALA immobilization prevents the platelet activation not only by reducing the protein adsorption capacity of the membranes but also by inhibiting the ROS production in blood. In a clinical study by Chang et al. [14] ALA administration in end-stage renal disease patients reduced the asymmetric dimethylargigine (ADMA) level in blood, which is indicative of decreased platelet aggregation [14].

\subsection{Activated partial thromboplastin time (APTT)}

All ALA immobilized membranes displayed significantly longer APTT values than the PSF, PSF-SPSF membranes and the control (Table 3). This can be explained by decreased adsorption of blood proteins and platelet activation on these mebranes. In addition, as 


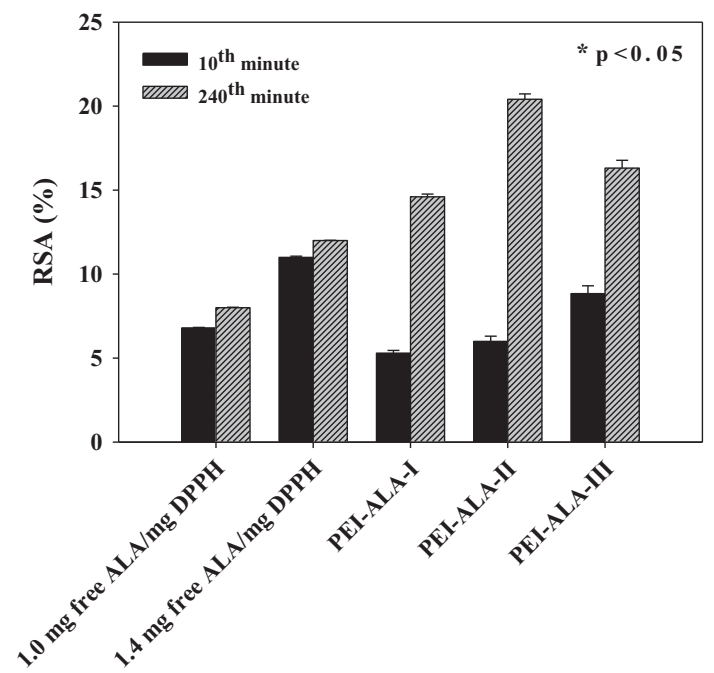

Fig. 7. \% RSA of free and immobilized ALA. *RSA (\%) values at 240th minute of immobilized ALA for each membranes are statistically different from each other and also that of same amount of free ALA $(p<0.05)$

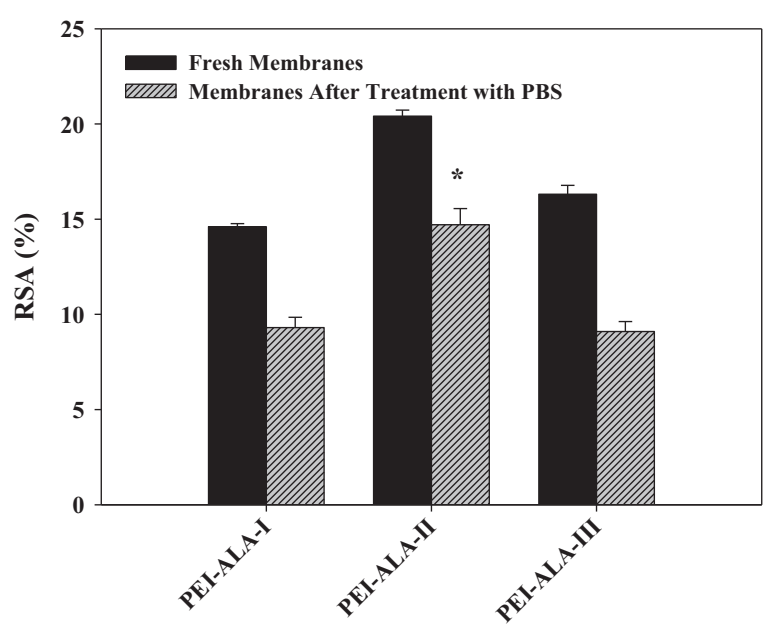

Fig. 8. The effect of storing time on the relative antioxidant activity of $\alpha$-lipoic acid immobilized on PSF membranes. Membranes were stored in phosphate buffer solution at $\mathrm{pH}=7.4, T=37{ }^{\circ} \mathrm{C}$ for $4 \mathrm{~h}$. ${ }^{*} \mathrm{RSA}(\%)$ value of PEI-ALA-II membrane is statistically different from PEI-ALA-I and PEI-ALA-III membranes after treatment $(p<0.05)$.

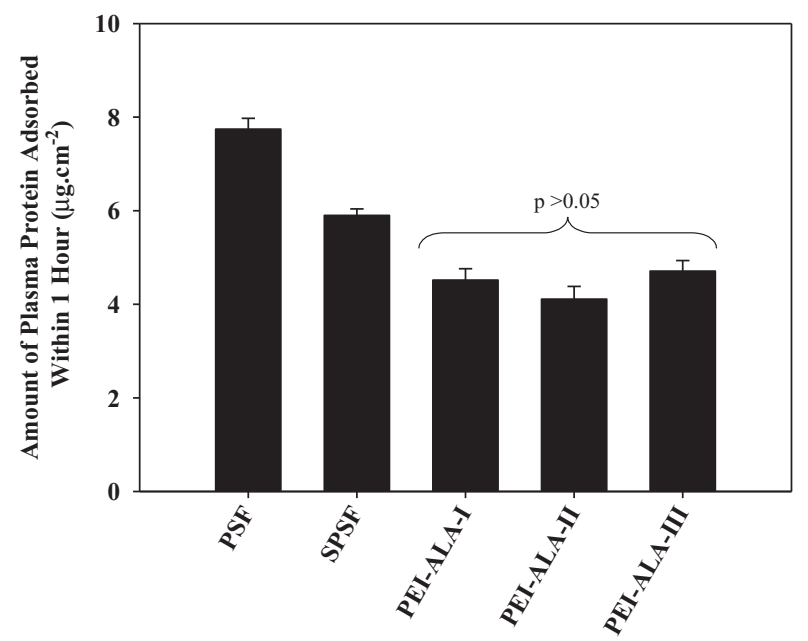

Fig. 9. The amount of blood plasma proteins adsorbed onto ALA coated PSF membranes.

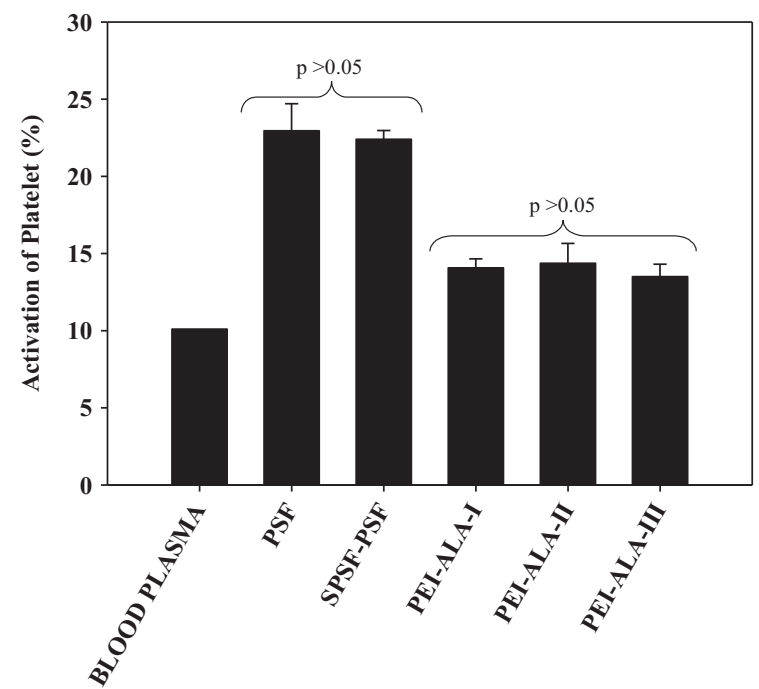

Fig. 10. Amount of platelet activation on the unmodified and modified PSF membranes.

will be discussed in the next section, the production of ROS is suppressed when blood is in contact with ALA deposited membranes, which helps to prolong the APTT through inhibition of intrinsic pathway. The results in Table 3 suggest that the ALA immobilization on the PSF membrane may allow to decrease the amount of anticoagulant injected to the patient during hemodialysis.

\subsection{Inhibition of reactive oxidant species in plasma}

The ability of uncoated and coated membranes in the inhibition of ROS in whole blood is shown in Fig. 12 where the ROS level was expressed as $\mathrm{CL}$ counts of $\mathrm{HOCl}$. The results show that the ALA immobilized on the SPSF-PSF membrane significantly suppressed the ROS formation in blood. The difference in the CL counts of $\mathrm{HOCl}$ obtained with the ALA loaded membranes and the control (blood incubated without any membrane) was found statistically insignificant $(p>0.05)$. Clinical studies showed that administration of ALA could decrease the biomarkers of hemodialysis induced oxidative stress in end-stage renal disease patients [14]. ALA is possibly rapidly converted to DHLA in many tissues after administrated. ALA and its reduced form DHLA redox couple effectively scavenge a number of free radicals, such as $\mathrm{H}_{2} \mathrm{O}_{2}, \mathrm{HOCl}$, and $\mathrm{O}^{-2}$ in both lipid and aqueous domains. On the other hand, other antioxidants used to modify hemodialysis membranes in previous studies are effective either in aqueous medium (vitamin C) or lipid environment (vitamin E). It has been noted that ALA is one of the most powerful antioxidant and also prooxidant for the other antioxidants in blood. The prooxidative property of ALA has been shown in studies (in vitro and in vivo) by regeneration of variety antioxidants including glutathione, vitamin $\mathrm{C}$, vitamin $\mathrm{E}$ and coenzyme Q10 [13].

\subsection{Cytotoxicity of PSF membranes}

A functional agent intended for biomedical applications should be nontoxic in its pure form. In this study, the cytotoxicity of pure ALA was not measured since it is administrated to hemodialysis patients to reduce complications caused by oxidative stress. As pointed out earlier, the maximum amount of ALA released from the membranes is lower than the amount orally taken by the hemodialysis patients. Cytotoxicity studies conducted with the membranes have shown that the viability of peripheral 


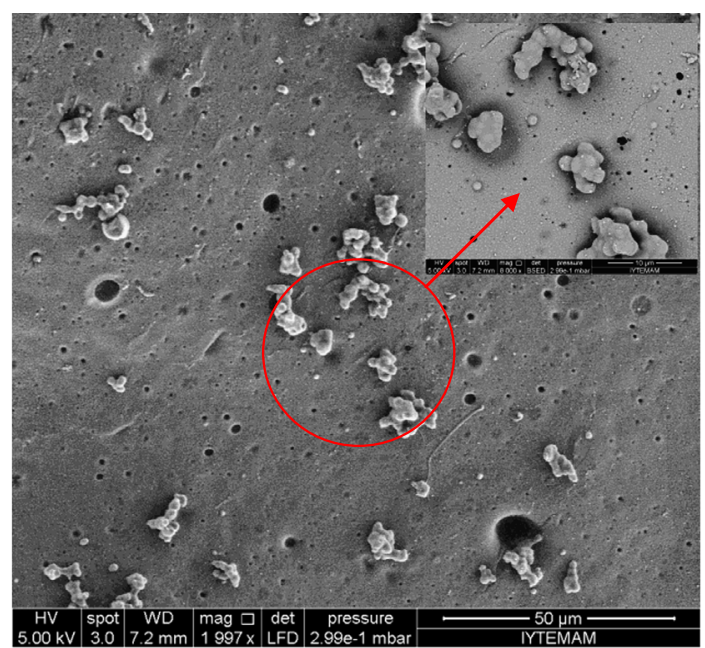

SPSF-PSF

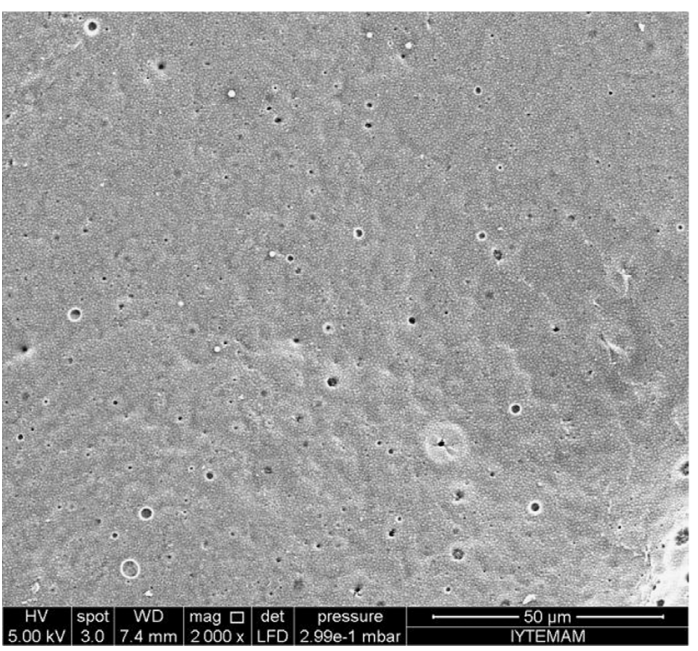

PEI-ALA-II

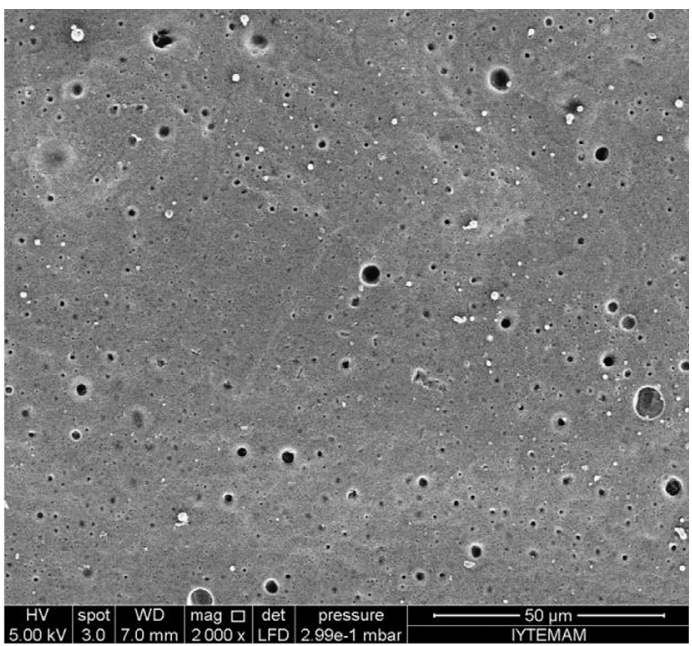

PEI-ALA-I

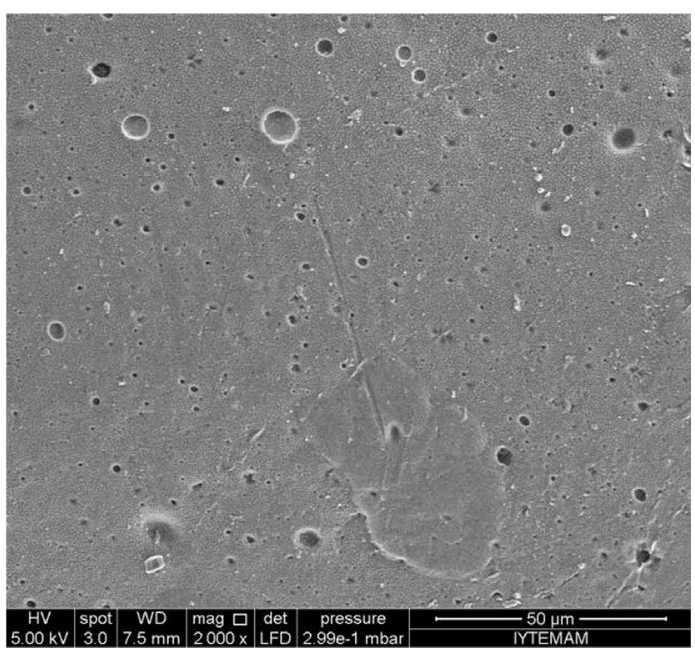

PEI-ALA-III

Fig. 11. The SEM pictures of unmodified and modified PSF membranes after incubating with PRP for 25 min, magnification $2000 \times$.

Table 3

The APTT values for modified and unmodified PSF membranes.

\begin{tabular}{ll}
\hline Sample & APTT (s) \\
\hline Control & $39 \pm 2$ \\
PSF & $37 \pm 3$ \\
PSF-SPSF & $38 \pm 3$ \\
PEI-ALA-I & $61 \pm 5$ \\
PEI-ALA-II & $57 \pm 2$ \\
PEI-ALA-III & $64 \pm 7$ \\
\hline
\end{tabular}

mononuclear blood cells (PMBC) after $4 \mathrm{~h}$ treatment with unmodified and modified membranes is close to $100 \%$ (Table 4 ). The excellent cell viability of the modified membranes confirms that the immobilization method proposed in this study does not have a significant negative effect on the nontoxic property of the unmodified PSF membrane.

\subsection{Permeation of solutes through unmodified and modified PSF-SPSF membranes}

To illustrate the influence of ALA immobilization on the transport properties of PSF membranes, permeation experiments were performed with the uncoated and two coated membranes. Urea

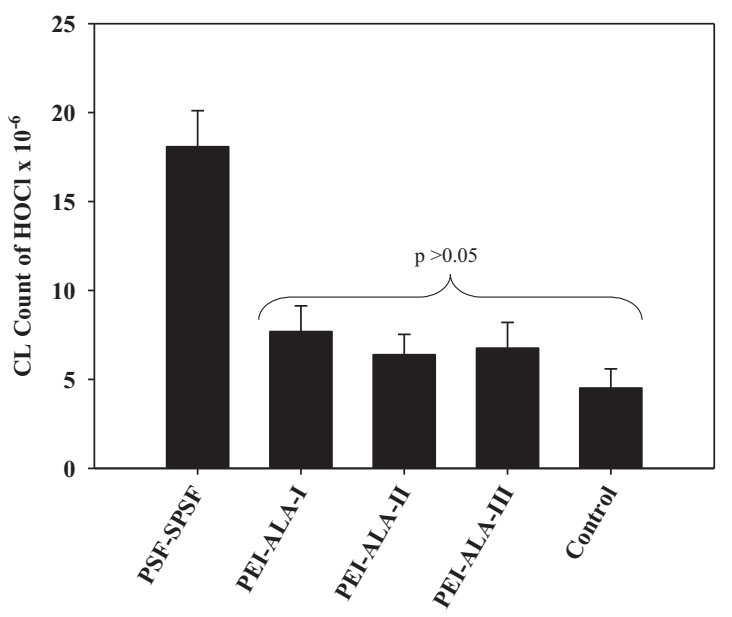

Fig. 12. The inhibition $\mathrm{HOCl}$ in blood by unmodified and modified membranes.

$\left(\mathrm{MW}=60 \mathrm{~g} \mathrm{~mol}^{-1}\right)$, vitamin $\mathrm{B}_{12}\left(\mathrm{MW}=1700 \mathrm{~g} \mathrm{~mol}^{-1}\right)$ and lysozyme $\left(\mathrm{MW}=14,600 \mathrm{~g} \mathrm{~mol}^{-1}\right.$ ) were choosen in order to simulate different sized solutes in blood. Fig. 13 shows that the permeation coefficients decrease exponentially with the increased molecular weight of the solutes as expected. The difference in the transport characteristics of 
Table 4

\% Live peripheral mononuclear blood cells after $4 \mathrm{~h}$ treatment with modified and unmodified PSF membranes.

\begin{tabular}{ll}
\hline Sample & Live cell (\%) \\
\hline Control & 100 \\
PSF & $99.6 \pm 0.2$ \\
PSF-SPSF & $98.1 \pm 0.3$ \\
PEI-ALA-I & $99.2 \pm 0.1$ \\
PEI-ALA-II & $98.6 \pm 0.5$ \\
PEI-ALA-III & $97.4 \pm 0.2$ \\
\hline
\end{tabular}

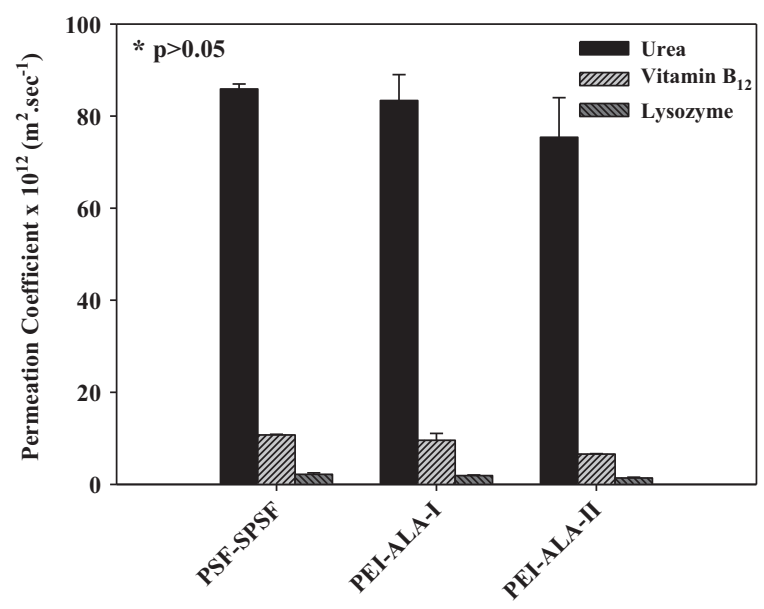

Fig. 13. The permeation coefficient of urea, vitamin $B_{12}$, lysozyme through PSF membranes. *Permeation coefficients of each membrane are not statistically different from each other for each solute $(p>0.05)$.

ALA loaded membranes was found statistically insignificant $(p>0.05)$. This was expected since only the surface of the membrane was modified, bulk structure remained unchanged due to polyelectrolyte deposition. Moreover, additional mass transfer resistance is rather small since the increase in the total thickness due to PEI-ALA deposition is negligible. The clearing performances of modified and unmodified PSF membranes for middle molecular weight model solutes lysozyme and vitamin $B_{12}$ are comparable with the results obtained with the industrial hemodialysis membranes AN69 $\left(1.5 \times 10^{-12} \mathrm{~m}^{2} \mathrm{~s}^{-1}\right.$ for $\mathrm{MW}=15,000 ; 4.0 \times 10^{-11} \mathrm{~m}^{2} \mathrm{~s}^{-1}$ for $\mathrm{MW}=$ $1700)$ and Cuprophan $\left(1.0 \times 10^{-13} \mathrm{~m}^{2} \mathrm{~s}^{-1} \quad \mathrm{MW}=15,000 ; 1.5 \times\right.$ $10^{-11} \mathrm{~m}^{2} \mathrm{~s}^{-1} \mathrm{MW}=1700$ ), reported by Langsdorf and Zydney [22]. In addition to model solutes, urea, vitamin $\mathrm{B}_{12}$ and lysozyme, the permeation of bovine serum albumin (BSA) was also studied. The results demonstrated that only $1-2 \%$ of the initial BSA can permeate through unmodified and ALA immobilized membranes. This means that the molecular weight cut-off values of the PSF membranes are approximately the same as the molecular weight of BSA (66.5 kDa) which is a required value for hemodialysis membranes to prevent loss of albumin in blood.

\section{Conclusion}

In this study, immobilization of ALA onto PSF based hemodialysis membranes is suggested to prevent hemodialysis induced oxidative stress. The immobilization method used in this study is novel in that it is based on site-specific binding of a carboxylic group of ALA to an ammonium group of anchoring polyelectrolyte layer-PEI-through electrostatic interactions. Consequently, the active site of ALA becomes available on the surface of the membrane to scavenge reactive oxygen species. This was demonstrated by the antioxidant activity results where the immobilization of ALA onto the
PSF membrane prolonged its stability under typical hemodialysis conditions. The highest antioxidant activity was obtained when ALA was sandwiched between two PEI layers. In vitro studies showed that ALA coated membranes are capable of reducing ROS levels in blood, protein adsorption and the platelet activation on the membranes. Furthermore, they can significantly prolong the APTT values without altering permeation rates. The antifouling and antioxidant properties of the membranes prepared with 1 and $5 \mathrm{mg} \cdot \mathrm{mL}^{-1}$ ALA are not significantly different; therefore, it is suggested to use the lower concentration during preparation. Based on the results it is fair to conclude that an ALA-immobilized PSF membrane could be an alternative membrane for preventing hemodialysis induced oxidative stress and may allow decreasing the amount of anticoagulant injected to the patient during hemodialysis.

\section{Acknowledgments}

We gratefully acknowledge support by L'Oreal Turkey "Women in Science Program". We also acknowledge Izmir Institute of Technology, Biotechnology and Bioengineering Research and Application Center and Material Research Center to provide facilities for performing the in vitro blood compatibility tests and SEM analysis and Professor Erhan Süleymanoğlu from Gazi University, Faculty of Pharmacy for XPS analysis.

\section{References}

[1] P. Jackson, C.M. Loughrey, J.H. Lightbody, P.T. McNamee, I.S. Young, Effect of hemodialysis on total antioxidant capacity and serum antioxidants in patients with chronic renal failure, Clinical Chemistry 41/8 (1995) 1135-1138.

[2] M. Maccarrone, S. Manca-di-Villahermosa, C. Meloni, R. Massoud, A. Mascali, R. Guarina, A. Finazzi-Agrò, M. Taccone-Gallucci, Arachidonate cascade, apoptosis, and vitamin $\mathrm{E}$ in peripheral blood mononuclear cells from hemodialysis patients, American Journal of Kidney Diseases 40/3 (2002) 600-610.

[3] G. Ferretti, T. Bacchetti, S. Masciangelo, G. Pallotta, Lipid peroxidation in hemodialysis patients: effect of vitamin C supplementation, Clinical Biochemistry 41 (2008) 381-386.

[4] V.D.A. Delfino, A.C.A. Vianna, A.J. Mocelin, D.S. Barbosa, R.A. Mise, T. Matsuo, Folic acid therapy reduces plasma homocysteine levels and improves plasma antioxidant capacity in hemodialysis patients, Applied Nutritional Investigation 23 (2007) 242-247.

[5] M. Mydlik, K. Derzsiova, O. Racz, A. Sipulova, E. Lovasova, J. Petrovicova, A modified diayzer with vitamin $\mathrm{E}$ and antioxidant defense parameters, Kidney International 59 (2001) 144-147.

[6] G. Clermont, L.S. Sandrine, J.F.C. Cabanne, G. Motte, J.C. Guilland, D. Chevet, L. Rochette, Vitamin E-coated dialyzer reduces oxidative stress in hemodialysis patient, Free Radical Biology \& Medicine 31 (2001) 233-241.

[7] K.I. Yamamato, M. Matsuda, M. Okuoka, T. Yakushiji, M. Fukuda, T. Miyasaka, Y. Matsumoto, K. Sakai, Antioxidation property of vitamin E-coated polysulfone dialysis membrane and recovery of oxidized vitamin E by vitamin C treatment, Journal of Membrane Science 302/15 (2007) 115-118.

[8] F.C. Kung, M.C. Yang, Effect of conjugated linoleic acid immobilization on the hemocompatibility of cellulose acetate membrane, Colloids and Surfaces B: Biointerfaces 47 (2006) 36-42.

[9] F.C. Kung, M.C. Yang, Effect of conjugated linoleic acid grafting on the hemocompatibility of polyacrylonitrile membrane, Polymers for Advanced Technologies 17 (2006) 419-425.

[10] F.C. Kung, M.C. Yang, The effect of covalently bonded conjugated linoleic acid on the reduction of oxidative stress and blood coagulation for polysulfone hemodialyzer membrane, International Journal of Biological Macromolecules 38 (2006) 157-164.

[11] F.C. Kung, M.C. Yang, The reduction of oxidative stress, anticoagulation of platelets, and inhibition of lipopolysaccharide by conjugated linoleic acid bonded on a polysulfone membrane, Polymers for Advanced Technologies 18 (2007) 286-291.

[12] C. Neelakandan, T. Chang, T. Alexander, L. Define, M. Evancho-Chapman, T. Kyu, In vitro evaluation of antioxidant and anti-inflammatory properties of genistein-modified hemodialysis membranes, Biomacromolecules 12 (2011) 2447-2455.

[13] L. Packer, E.H. Witt, H.J. Tritschler, Alpha-lipoic acid as a biological antioxidant, Free Radical Biology \& Medicine 19 (1995) 227-250.

[14] J.W. Chang, E.K. Lee, T.H. Kim, W.K. Min, S. Chun, K.U. Lee, S.B. Kim, J.S. Park, Effects of alpha-lipoic acid on the plasma levels of asymmetric dimethylarginine in diabetic end-stage renal disease patients on hemodialysis: a pilot study, American Journal of Nephrology 27 (2007) 70-74. 
[15] I. Ford, M.A. Cotter, N.E. Cameron, M. Greaves, The effects of treatment with alipoic acid or evening primrose oil on vascular hemostatic and lipid risk factors, blood flow, and peripheral nerve conduction in the streptozotocindiabetic rat, Metabolism 50 (2001) 868-875.

[16] S.A. Marsh, J.S. Coombes, Vitamin E and a-lipoic acid supplementation increase bleeding tendency via an intrinsic coagulation pathway, Clinical Applied Thrombosis/Hemostasis 12 (2006) 169-173.

[17] K. Kofuji, M. Nakamura, T. Isobe, Y. Murata, S. Kawashima, Stabilization of a-lipoic acid by complex formation with chitosan, Food Chemistry 109 (2008) 167-171.

[18] K. Kofuji, T. Isobe, Y. Murata, Controlled release of alpha-lipoic acid through incorporation into natural polysaccharide-based gel beads, Food Chemistry 115 (2009) 483-487.

[19] R. Weerakody, P. Fagan, S.L. Kosaraju, Chitosan microspheres for encapsulation of alpha-lipoic acid, International Journal of Pharmaceutics 357 (2008) 213-218.
[20] S. Trombino, R. Cassano, E. Bloise, R. Muzzalupo, S. Leta, F. Puoci, N. Picci, Design and synthesis of cellulose derivatives with antioxidant activity, Macromolecular Bioscience 8 (2008) 86-95.

[21] J.C. Jansen, R. Cassano, S. Trombino, A. Cilea, N. Picci, E. Drioli, L. Giorno, Polymeric membranes with antioxidant activity based on cellulose esters and poly(vinylidene fluoride)/cellulose ester blends, Cellulose 18 (2011) 359-370.

[22] L.J. Langsdorf, A.L. Zydney, Diffusive and convective solute transport through hemodialysis membranes: a hydrodynamic analysis, Journal of Biomedical Materials Research 28 (1994) 573-582.

[23] W. Ruixia, C. Jinlong, C. Lianlong, F. Zheng-hao, L. Ai-min, Z. Quanxing, Study of adsorption of lipoic acid on three types of resin, Reactive \& Functional Polymers 59 (2004) 243-252.

[24] J. Teichert, T. Tuemmers, H. Achenbach, C. Preiss, R. Hermann, P. Ruus, R. Preiss, Pharmacokinetics of alpha-lipoic acid in subjects with severe kidney damage and end-stage renal disease, Journal of Clinical Pharmacology 45 (2005) 313-328. 